\title{
Tracheal agenesis: Salvaging the unsalvageable
}

\author{
Roosevelt Bryant III, MD
}

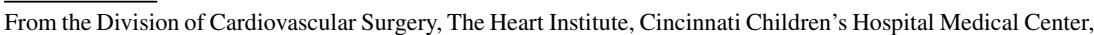
Cincinnati, Ohio.

Disclosures: Author has nothing to disclose with regard to commercial support.

Received for publication Jan 23, 2017; accepted for publication Jan 28, 2017; available ahead of print Feb 24, 2017.

Address for reprints: Roosevelt Bryant III, MD, Pediatric Heart Transplant Program, Cincinnati Children's Hospital Medical Center, The University of Cincinnati College of Medicine, 3333 Burnet Ave, MLC 2004, Cincinnati, OH 45229 (E-mail: Roosevelt.BryantIII@ cchmc.org).

J Thorac Cardiovasc Surg 2017;153:e127

0022-5223/ $\$ 36.00$

Copyright (C 2017 by The American Association for Thoracic Surgery

http://dx.doi.org/10.1016/j.jtcvs.2017.01.039
}

When Floyd and colleagues ${ }^{1}$ described tracheal agenesis in their seminal 1962 report, there were only 12 other such cases reported in the literature. From their review of that clinical experience, the Floyd classification scheme for tracheal agenesis evolved. At the time, none of the reported patients had survived, including the subject of their report. The patients were either stillborn or died shortly after birth. Floyd type II tracheal agenesis accounts for $50 \%$ to $60 \%$ of all cases of tracheal agenesis. ${ }^{2}$ In this subtype, the bronchi and bifurcation are normal, with complete atresia of the proximal airway. This type of tracheal agenesis and its surgical management is the subject of the case report in this issue of the Journal by Densmore and colleagues. ${ }^{3}$ Salvage treatment of a critically ill neonate with tracheal agenesis is contingent on the presence of a tracheoesophageal or bronchoesophageal fistula, which allows esophageal intubation and mechanical ventilation. Prenatal diagnosis is rare and only suspected in the absence of a tracheoesophageal fistula. Absence of a tracheoesophageal fistula results in congenital high airway obstruction. Congenital high airway obstruction presents with a dilated, fluid-filled, blind ending proximal tracheal pouch, absence of air in the distal bronchi, and enlarged, echogenic lung fields. In the absence of congenital high airway obstruction, the diagnosis is suspected after birth when there is absence of a cry, respiratory distress without appropriate air entry into the lungs, and failure of endotracheal intubation. ${ }^{4}$ Esophageal intubation is lifesaving.

Tracheal agenesis is a nearly uniformly fatal disease after birth. Surgical repair of this congenital anomaly in survivors outside of the United States has used "neotrachealization" of the esophagus with external stenting. In 4 survivors reported

\section{References} 1962;86:557-60. Surg. 2017; 153:e121-5. 425-31.

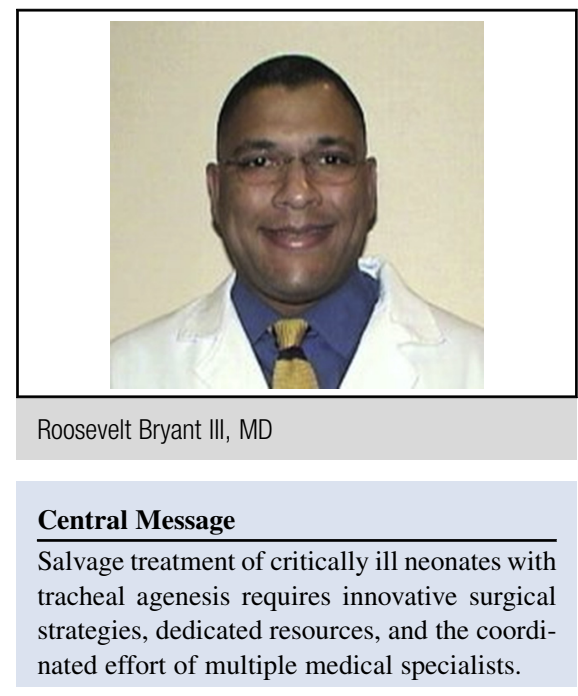

See Article page e121.

from Osaka University, gastrointestinal continuity was established by gastric or jejunal interposition. ${ }^{5}$ Densmore and colleagues $^{3}$ have modified this surgical approach to save a particularly high-risk patient who had a nearly atretic tracheoesophageal fistula and concerns for neurologic insult from postnatal hypoxia. Their report speaks to the coordinated effort required of multiple medical specialists, and the resources required at a tertiary care facility, to achieve a truly remarkable outcome for the patient and family.

1. Floyd J, Campbell DC Jr, Dominy DE. Agenesis of the trachea. Am Rev Respir Dis.

2. Ergun S, Tewfik T, Daniel S. Tracheal agenesis: a rare but fatal congenital anomaly. Mcgill J Med. 2010;13:10-2.

3. Densmore JC, Oldham KT, Dominguez KM, Berdan ER, McCormick ME Beste DJ, et al. Neonatal esophageal trachealization and esophagocarinoplasty in the treatment of flow-limited Floyd II tracheal agenesis. J Thorac Cardiovasc

4. de Groot-van der Mooren M, Haak MC, Lakeman P, Cohen-Overbeek TE, van der Voorn JP, Bretschneider JH, et al. Tracheal agenesis: approach towards this severe diagnosis. Case report and review of the literature. Eur J Pediatr. 2012;171:

5. Tazuke Y, Okuyama H, Uehara S, Ueno T, Nara K, Yamanaka H, et al. Long-term outcomes of four patients with tracheal agenesis who underwent airway and esophageal reconstruction. J Pediatr Surg. 2015;50:2009-11. 